\title{
Admission to hospital for road trauma in patients with diabetes mellitus
}

\author{
NICHOLAS H DE KLERK AND BRUCE K ARMSTRONG
}

From NH and MRC Research Unit in Epidemiology and Preventive Medicine, Department of Medicine, University of Western Australia, Nedlands, W Australia

SUMMARY A total of 8623 patients admitted to hospital in Western Australia with a diagnosis of diabetes mellitus during 1971-9 were linked with hospital admissions for road trauma during the same period, and their admission rates compared with the whole population. Although there was no overall difference, there was a significant excess of admissions in diabetic men aged under 55, the excess being produced by those in control of a vehicle and pedestrians. There were smaller excesses in the same female age group and a corresponding deficit in older diabetics. The results are limited through being based on routinely collected data on hospital admissions both for diabetics and victims of road crashes but indicate that there is a real problem of road accidents among diabetics that should be more fully investigated with a population based study that would collect important additional information unavailable in this study.

The occurrence of road crashes due to hypoglycaemia in insulin dependent diabetic drivers is a well recognised potential hazard attested to by several case reports-for example, Herner et $\mathrm{ll}^{1}$ and Leyshon et al. ${ }^{2}$ The frequency of insulin induced hypoglycaemia as a cause of road crashes, however, is low-of the order of $0 \cdot 1 / 1000$ crashes reported to the police or requiring their investigation. ${ }^{13}$ Such estimates, however, are imprecise (based on four and one crashes respectively attributed to hypoglycaemia) and suffer from the uncertainties of retrospective assignment of causation.

The actual risk that a diabetic will suffer a road crash, relative to that of apparently well people, has been estimated in several studies. Waller ${ }^{4}$ reported the rates over three years of road crashes and road traffic offences in 287 diabetics known to the California Department of Motor Vehicles and 926 randomly selected other drivers. The diabetics recorded 15.5 crashes and 4.6 offences per one million miles driven compared with 8.7 crashes and 3.3 offences per million miles expected from the experience of the random sample. The estimated annual average miles driven by the diabetics differed little from that in the comparison group. Crancer and McMurray ${ }^{5}$ also found higher rates of road crashes and traffic offences in 79 months of follow up of 7647 diabetics in Washington State subject to medical restrictions on their licence to drive. The excess, however, was present only in men and mainly those aged 50 years or younger. The relative increase was less than in Waller's study ${ }^{4}(30-40 \%$ excess risk of road crash in men under 50) but was based on a person years denominator not miles driven. Both studies were of diabetic drivers known to the licensing authorities-some $25 \%$ of Crancer and McMurray's $^{5}$ full group of medically restricted drivers were so known because of reporting by the courts, enforcement officers, or concerned citizens and may, therefore, have been a group prone to crash. Both also depended, for ascertainment of less severe crashes, on voluntary notification, which could have been less frequent in the potentially compromised driver.

In contrast to these studies Ysander, ${ }^{6}$ when for an average of 4.5 years he followed up 256 diabetic drivers and a comparison group matched for age, sex, and duration of licence holding in Sweden, found a lower rate of road crash and traffic offences in the diabetics than in the comparison group. $\mathrm{He}$ attributed this to the surveillance under which the diabetic drivers were kept. A sample survey suggested that diabetics and comparison subjects differed little in the annual average miles driven. Another study by the same author, ${ }^{7}$ however, of 219 diabetics indicated that $21 \%$ of diabetics (mainly aged over 50) had ceased driving after diagnosis of their disease compared with $9 \%$ of controls who had 
ceased driving over the same period.

The evidence, therefore, conflicts as to whether diabetic drivers do show a detectable increase in risk of having a road crash. Because the fitness of diabetics to drive is currently under active consideration in Australia and has been the subject of recent comment in Britain ${ }^{8}{ }^{9}$ this study was undertaken to see whether additional information could be obtained. It used existing data by means of record linkage and is limited in several respects; the results may, however, point the way to useful further investigations.

\section{Methods}

An abstract of morbidity, identified by name and other relevant variables (date and place of birth, occupation, postcode of residence, etc) has been collected by the Public Health Department of Western Australia on all patients discharged from all hospitals in Western Australia since 1 January 1971. The morbidity information provided includes the major diagnosis, major complication (if any), external cause (of any injury), and another condition present (if any). These abstracts are stored in computer files.

All patients born before 1965 with any mention of diabetes mellitus (ICD 8 and 9 codes 2500 to 2509) on their discharge abstract in the years 1971 to 1979 were selected for inclusion in the study, provided that:

(a) a road crash (ICD 8 and $9 \mathrm{E}$ codes 8100 to 8279) was not the external cause of the identifying admission;

(b) the patients' name was present on the record; and

(c) their earliest admission did not terminate in death in hospital.

Records relating to the same person were linked together using a suite of linkage programs that, in addition to overcoming problems of inaccurate or missing data, are able to identify most links when a change of surname has occurred. Extensive validation of the linkage methods has shown that between $2 \%$ and $5 \%$ of true links are missed and under $1 \%$ of links made are false. Six per cent of admissions did not have the name available.

All patients with a road crash as the external cause of admission were then selected, again subject to presence of the patient's name on the record, and linked to the records with mention of diabetes mellitus.

Linkage using the same computer programs was also carried out between the cohort of diabetics and computerised records of all people who died in
Western Australia from 1971 to 1979 . It was thus possible to determine the date and cause of death of any of the diabetics who had died in Western Australia before 31 December 1979.

After completion of the linkages, the numerators for the rate calculations were determined by counting the numbers of admissions for road trauma (road crash as external cause), or deaths, linked to the cohort of diabetics after the earliest admission for diabetes. The denominators were derived from the aggregate of person years accumulated by the diabetics from discharge after their earliest admission until death or 31 December 1979, whichever was earlier.

Expected numbers of admissions for road trauma in the diabetics were estimated by first calculating admission rates (in 10 year age groups) for the whole population of Western Australia from the road trauma admissions selected-that is, all those which included patient names - and then applying them on an age specific basis to the person years of follow up accumulated by the diabetics. Expected numbers of deaths were similarly calculated from the death rates in the whole population over the period of study.

Confidence intervals for the rate ratios were estimated from tables published by Bailar and Ederer. ${ }^{10}$

\section{Results}

A total of 8623 patients with diabetes mellitus were identified who, to death or 31 December 1979, were followed up for 27453 person-years (table 1).

ADMISSIONS TO HOSPITAL AFTER ROAD CRASHES Altogether, 72 admissions after road crashes were observed in diabetics compared with 73.0 expected from the population rates (table 2). There was, however, a substantial excess of admissions in diabetic men aged 15 to 54 (36 observed, 21.2 expected) and a smaller excess in diabetic women of the same age (12 observed, 10.2 expected). There were corresponding deficits of admissions in older diabetics.

Table 3 shows observed and expected numbers of admissions in diabetics according to whether the patient was a vehicle driver, motor or pedal cyclist, passenger in a vehicle, pedestrian, or this information was not specified in the medical record. There was a significant excess of admissions in diabetic men in control of a vehicle (vehicle driver, pedal or motor cyclist) with an observed number of 29 and an expected number of 17.9 (ratio $1.62, p<0.05$ ). This excess was confined to those under $55(23 / 10 \cdot 0$, ratio $2 \cdot 30, \mathrm{p}<0 \cdot 01)$. The overall deficits of admissions in male diabetic passengers and pedestrians were more 
pronounced in the elderly. There was, however, a significant excess of admissions $(7 / 1 \cdot 5$, ratio $4 \cdot 67$, $\mathrm{p}<0.01)$ in male pedestrians under 55 .

There was no appreciable excess of admissions in diabetic women in control of a vehicle, either overall at all ages (ratio 1.03) or in those under 55 (ratio $1 \cdot 11)$. There were deficits in most of the other categories.

For all admissions the percentage in which the road user's status - that is whether driver, passenger, pedestrian, etc-was unspecified was $33.6 \%$; in diabetic admissions it was $23.6 \%$ (difference not statistically significant). In men aged under 55 the corresponding percentages were 33.1 and $16.7 \%$ (again not statistically significant $0 \cdot 1>p>0 \cdot 05$ ). These percentages suggest a tendency for the status of young diabetic men to be specified better than non-diabetic men although in this age group there was a significant excess of admissions in diabetics regardless of status.

It proved possible to correct for possible bias in the road users of unspecified status by computing observed and expected numbers of admissions to hospital according to whether subjects, at initial ascertainment, were residents of the Perth Statistical Division (the City of Perth and its immediately surrounding areas) or the rest of (rural) Western Australia. Unspecified status admissions were most common in rural hospitals and comprised 13 of 21 admissions in diabetics resident in rural areas compared with four of 51 admissions (two of 32 admissions in men and two of 19 in women) in diabetics resident in the Perth Statistical Division. Analyses confined to Perth residents showed a similar pattern to that displayed in table 3 . Specifically, the observed to expected ratios in men aged 15-54 were: vehicle drivers $3.66(15 / 4 \cdot 1$; $\mathrm{p}<0.01)$, motor and pedal cyclists $1.72(5 / 2.9)$; passengers $0.00(0 / 1 \cdot 6)$, pedestrians $3.67(4 / 1 \cdot 1)$, and unspecified $1.06(2 / 1.9)$. In rural men aged 15 to 54 the observed to expected ratio was $1 \cdot 10(2 / 1 \cdot 8)$ in vehicle drivers and the only other ratio to exceed 1.0 was in pedestrians where it was $7 \cdot 14(3 / 0 \cdot 42)$.

Five of the road crash admissions in diabetic men aged 15 to 54 were contributed by one man. In this age group, however, four diabetics had multiple admissions for road trauma compared with $\mathbf{3 \cdot 2}$ expected from the distribution of multiple admissions among all admissions for road trauma in young men. There was no evidence of an excess of multiple admissions in older diabetic men or diabetic women.

Table 1 Numbers of patients with diabetes mellitus in the cohort, numbers of deaths, and numbers of person years accumulated to 31 December 1979

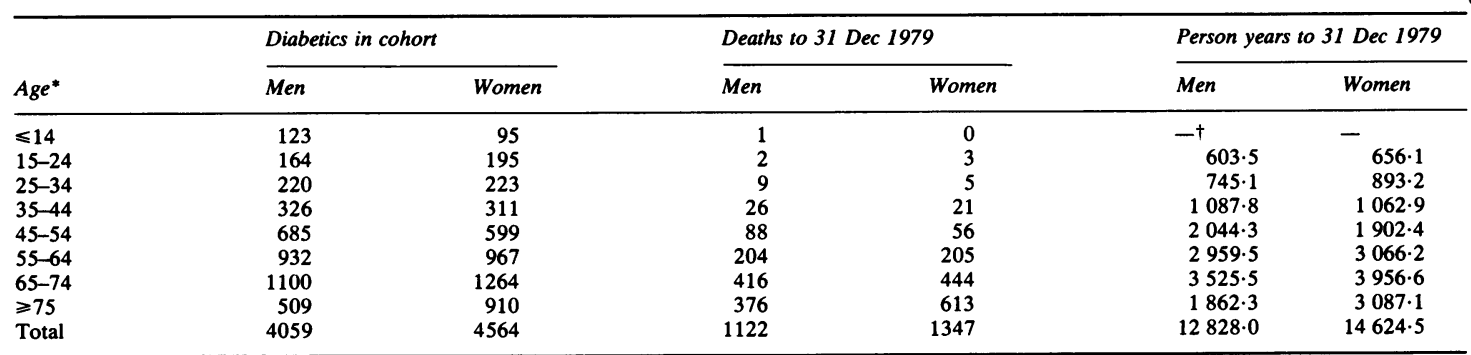

* Refers respectively to age at identifying admission, age at death, and age during follow up.

†All rates were based only on events occurring in those aged 15 or older.

Table 2 Observed and expected numbers of hospital admissions after road crashes in patients with diabetes mellitus

\begin{tabular}{|c|c|c|c|c|c|c|c|c|}
\hline \multirow[b]{2}{*}{ Age } & \multicolumn{4}{|l|}{ Men } & \multicolumn{4}{|l|}{ Women } \\
\hline & Observed & Expected & $O b s / E x p$ & $95 \% C L$ & Observed & Expected & Obs/Exp & $95 \% C I$ \\
\hline $15-24$ & 11 & $7 \cdot 7$ & 1.43 & $0.72-2.56$ & 0 & $3 \cdot 1$ & 0 & - \\
\hline $25-34$ & 7 & 3.9 & 1.79 & $0.72-3.69$ & 5 & 1.9 & $2 \cdot 63$ & $0.85-6.14$ \\
\hline $35-44$ & 5 & 3.6 & $1 \cdot 39$ & $0.45-3.25$ & 3 & $2 \cdot 0$ & $1 \cdot 50$ & $0.31-4.39$ \\
\hline $45-54$ & 13 & 6.0 & $2 \cdot 17$ & $1 \cdot 15-3.71$ & 4 & $3 \cdot 2$ & $1 \cdot 25$ & $0.34-3.20$ \\
\hline $55-64$ & 2 & $7 \cdot 8$ & 0.26 & $0.30-0.94$ & 7 & $5 \cdot 6$ & $1 \cdot 25$ & $0.50-2.58$ \\
\hline 65-74 & 8 & $9 \cdot 1$ & 0.88 & $0.28-1.73$ & 4 & $8 \cdot 1$ & 0.49 & $0 \cdot 13-1 \cdot 25$ \\
\hline$\geqslant 75$ & 1 & $5 \cdot 4$ & 0.19 & $0.05-1.06$ & 2 & $5 \cdot 8$ & 0.34 & $0.04-1.23$ \\
\hline Total & 47 & $43 \cdot 5$ & 1.08 & $0.79-1.44$ & 25 & $29 \cdot 6$ & 0.84 & $0.54-1.24$ \\
\hline
\end{tabular}


Table 3 Observed and expected numbers of hospital admissions after road crashes in patients with diabetes mellitus according to the patients' road use status at the time

\begin{tabular}{|c|c|c|c|c|c|c|c|}
\hline \multirow[b]{2}{*}{ Road use status } & & \multicolumn{3}{|l|}{ Men } & \multicolumn{3}{|l|}{ Women } \\
\hline & & $15-54$ years & $\geqslant 55$ years & All ages & $15-54$ years & $\geqslant 55$ years & All ages \\
\hline \multirow[t]{3}{*}{ Vehicle driver } & Observed & 17 & 5 & 22 & 2 & 3 & 5 \\
\hline & Expected & $6 \cdot 1$ & $6 \cdot 5$ & $12 \cdot 6$ & $2 \cdot 3$ & $2 \cdot 9$ & $5 \cdot 2$ \\
\hline & Obs/Exp & $2 \cdot 79+$ & 0.77 & 1.75 & 0.87 & 1.03 & 0.96 \\
\hline \multirow[t]{3}{*}{ Motor and pedal cyclists } & Observed & 6 & 1 & 7 & 1 & 0 & 1 \\
\hline & Expected & 3.9 & 1.4 & $5 \cdot 3$ & 0.4 & 0.2 & 0.6 \\
\hline & Obs/Exp & $1 \cdot 54$ & 0.71 & $1 \cdot 32$ & $2 \cdot 5$ & 0 & 1.67 \\
\hline \multirow[t]{3}{*}{ Vehicle passenger } & Observed & 0 & 1 & 1 & 5 & 3 & 8 \\
\hline & Expected & $2 \cdot 5$ & $2 \cdot 2$ & $4 \cdot 7$ & $2 \cdot 9$ & $6 \cdot 0$ & $8 \cdot 9$ \\
\hline & Obs/Exp & 0 & 0.45 & 0.21 & $1 \cdot 72$ & $0 \cdot 50$ & 0.90 \\
\hline \multirow[t]{3}{*}{ Pedestrian } & Observed & 7 & 0 & 7 & 1 & 3 & 4 \\
\hline & Expected & $1 \cdot 5$ & $6 \cdot 0$ & $7 \cdot 5$ & 0.7 & $5 \cdot 1$ & $5 \cdot 8$ \\
\hline & Obs/Exp & $4 \cdot 67 \dagger$ & $0 \ddagger$ & 0.93 & 1.43 & 0.59 & 0.69 \\
\hline \multirow[t]{3}{*}{ Unspecified } & Observed & 6 & 4 & 10 & 3 & 4 & 7 \\
\hline & Expected & $7 \cdot 2$ & $6 \cdot 2$ & $13 \cdot 4$ & 3.8 & $5 \cdot 2$ & $9 \cdot 0$ \\
\hline & Obs/Exp & 0.83 & 0.65 & 0.75 & 0.79 & 0.77 & 0.78 \\
\hline \multirow[t]{3}{*}{ Total } & Observed & 36 & 11 & 47 & 12 & 13 & 25 \\
\hline & Expected & $21 \cdot 2$ & $22 \cdot 3$ & $43 \cdot 5$ & $10 \cdot 1$ & $19 \cdot 4$ & 29.5 \\
\hline & Obs/Exp & $1 \cdot 70^{\dagger}$ & $0.49^{*}$ & 1.08 & $1 \cdot 19$ & 0.67 & 0.85 \\
\hline
\end{tabular}

*Obs/exp ratio significantly different from $1 \cdot 0, p<0 \cdot 05$.

tObs/exp ratio significantly different from $1 \cdot 0, p<0 \cdot 01$.

$\ddagger$ Probability of observing 0 events from a Poisson distribution of mean 6 is less than 0.01 .

NATURE OF INJURY, REASON FOR ADMISSION AND DURATION OF STAY

It would be reasonable to postulate that the combination of two problems, road trauma and diabetes mellitus, would be more likely to lead to admission to hospital than road trauma alone. ${ }^{11}$ If true, diabetics admitted for road trauma would probably have less serious injuries, on average, than other people. Table 4 compares the distribution of categories of nature of injury (grouped ICD N codes) after a road crash in diabetics and others.

In young diabetic men the observed distribution of nature of injury differed significantly from that expected $\left(\chi_{8}^{2}=17 \cdot 65 ; p<0 \cdot 025\right)$. It showed excesses of admissions for head injury $(15 / 10 \cdot 8)$ and other and unspecified injury $(5 / 1 \cdot 2)$ and a corresponding deficit of admissions for fractures $(7 / 12 \cdot 0)$. Of the five with other and unspecified injuries, two were car drivers, two motorcyclists, and one was unspecified, and the injuries were to the trunk (2), face or neck (2), and leg (1).

The geometric mean durations of stay after admission for road trauma were 4.9 days in diabetics and 3.8 days in all other patients (difference not statistically significant). This longer than average stay was present in diabetic men and women aged under 55 but not in older diabetics. While a shorter average might have been indicative of less severe injuries in diabetics, the converse cannot be inferred from a longer average stay. Loss of control of diabetes would be common after admission to hospital and would tend to lengthen stay.

The hospital records of diabetic men aged 15-54 who had been in control of a vehicle were reviewed to

Table 4 Observed and expected numbers of road crash injuries leading to admission to hospital by nature of injury in patients with diabetes mellitus

\begin{tabular}{|c|c|c|c|c|c|c|c|c|}
\hline \multirow[b]{3}{*}{ Nature of injury } & \multicolumn{4}{|l|}{ Men } & \multicolumn{4}{|c|}{ Women } \\
\hline & \multicolumn{2}{|c|}{$15-54$ years } & \multicolumn{2}{|c|}{$\geqslant 55$ years } & \multicolumn{2}{|c|}{$15-54$ years } & \multicolumn{2}{|c|}{$\geqslant 55$ years } \\
\hline & Obs & $\operatorname{Exp}{ }^{*}$ & Obs & $\operatorname{Exp}$ & Obs & $\operatorname{Exp}$ & Obs & $\operatorname{Exp}$ \\
\hline Fractures & 7 & $11 \cdot 95$ & 4 & $4 \cdot 83$ & 4 & $3 \cdot 30$ & 5 & $6 \cdot 31$ \\
\hline Dislocations, strains, and sprains & 1 & $1 \cdot 31$ & 1 & 0.39 & 1 & 0.68 & $\mathbf{0}$ & 0.44 \\
\hline Intracranial injury (mainly concussion) & 15 & $10 \cdot 85$ & 2 & $2 \cdot 67$ & 2 & 3.66 & 3 & $2 \cdot 31$ \\
\hline Internal injury of chest, abdomen, and pelvis & 0 & $1 \cdot 12$ & 0 & $0 \cdot 38$ & 0 & 0.32 & 1 & 0.44 \\
\hline Open wounds and lacerations & 4 & $4 \cdot 80$ & 0 & $1 \cdot 29$ & 1 & $1 \cdot 51$ & 0 & $1 \cdot 39$ \\
\hline Superficial injury, contusions, and crushing & 2 & $2 \cdot 25$ & 2 & 0.46 & 2 & 0.87 & 2 & 1.05 \\
\hline Shock and other effects of trauma & 2 & 1.88 & $\overline{1}$ & 0.45 & 1 & 0.93 & 1 & 0.62 \\
\hline Injury, other and unspecified & 5 & $1 \cdot 23$ & 1 & 0.34 & 1 & 0.51 & 1 & $0 \cdot 27$ \\
\hline All others & 0 & 0.61 & 0 & $0 \cdot 20$ & 0 & 0.22 & 0 & $0 \cdot 17$ \\
\hline Total & 36 & 36 & 11 & 11 & 12 & 12 & 13 & 13 \\
\hline
\end{tabular}

*Calculated from the relative frequencies of the same injury groupings within the same age/sex groups in the whole population. 
see whether their diabetes had contributed to a decision in favour of admission to hospital after road trauma. Records were available for 22 of 23 such admissions in 16 diabetics; 13 of the 16 were being treated with insulin. At most it appeared that in three admissions the decision to admit was influenced by the fact of diabetes. Two were for minor episodes of concussion in which diabetes was mentioned among the reasons for admission and one was for cellulitis of the leg that developed several days after injury and diabetes was mentioned in the referring letter.

DEATHS FROM ROAD TRAUMA

The ratio of observed to expected deaths from all causes was $2.95(2468 / 837 \cdot 7)(p<0 \cdot 01)$. There were fewer deaths from road trauma than expected $(6 / 13.4)$ (ratio $0.45, p<0.05)$, but for men under 55 there were slightly more than expected $(3 / 1.9)$ (ratio 1.57).

\section{Discussion}

Our results suggest an increased risk of admission to hospital for road trauma in young diabetic men in charge of a vehicle. Several factors, however, may have biased the results and thus made their interpretation difficult.

Firstly, there may have been some underestimation of the numbers of admissions for road trauma in diabetics because of the missed true links referred to in the methods section. In addition a few links in young diabetic women may have been missed because of changes in name through marriage. The expected numbers of admissions may have been overestimated because the population at risk was overestimated through missed links to death records and non-identification of deaths that occurred outside Western Australia. The result of these biases would be, most likely, a reduction in the observed to expected ratios.

Secondly, as mentioned in the results, a diabetic who suffers road trauma may be more likely to be admitted to hospital than a non-diabetic with similar injuries. There was some evidence, particularly in young men, that injuries in diabetics were less severe than in all patients admitted for road trauma. Such an effect would be expected to be most evident in younger diabetics who are more likely to be insulin dependent and therefore to lose control of their diabetes after injury. It is difficult to see, however, why this should produce an excess of admissions in men but not women. An excess due to selective admission would also be expected to apply over all categories of road user. The excess in young diabetic men applied to drivers and pedestrians (but not passengers)-that is to individuals whose own behaviour may have contributed to the road crash.
Thirdly, the diabetics were selected from hospital records; they may therefore have been more sick or experiencing more problems with their diabetes than diabetics in general and thus likely to have an atypical road crash experience. The net effect of this bias cannot be calculated. Unstable insulin dependent diabetics are probably more prone both to admission to hospital and to road crashes, whereas sick diabetics may be less inclined to drive a vehicle or to travel whether as a driver or not. There are some indications that chronically ill people drive less than well people. ${ }^{4}$ This effect could explain the comparatively low admission rates for road trauma in older diabetics.

Fourthly, in addition to the actual amount of driving, account could not be taken of the nature of the vehicle usually driven (insulin dependent diabetics in Western Australia who are known to licensing authorities are reviewed medically and are likely to be restricted in their driving of public service and heavy goods vehicles), the time of day of driving, the duration of driving spells, the frequency of city versus country driving, etc, all factors that may differ between diabetics and other drivers and may influence road crash rates. ${ }^{12}$

We think that these various biases cannot explain the excess of admissions for road trauma in young diabetic men; the size of the excess, however, must be considered as uncertain.

Our results are similar to those obtained by Crancer and $\mathrm{McMurray}^{5}$ who also found an excess risk of road crashes confined to young diabetic men. The relative risk in their study was of the order of 1.3 to 1.4 . As it was based on reported accidents it may have been somewhat of an underestimate due to selective underreporting of accidents by diabetics who may have viewed their licence to drive as being under threat.

Given the extent to which diabetics are subject to medical surveillance of their licence to drive, or restricted in their access to licensing, it is surprising that adequate studies have not been conducted to determine the true size of the problem of road crashes among them, both for the diabetics themselves and for the community at large. Such studies would permit an estimate of the benefits of restrictions (if they are at all effective) with which the costs could be compared. Ideally they would deal with representative samples of diabetics whose mode of treatment was known, include an appropriate comparison group of apparently well people, document all road crashes giving rise to human injury or property damage, not just those notified to traffic authorities or leading to admission to hospital, and control for other personal factors known to influence road crash rates, particularly actual distance driven. 
Access to the data and computer facilities for this project were provided through the courtesy of the Public Health Department of Western Australia. Our interest in the problem was stimulated by Dr T A Welborn, and some funds for clerical help were provided by the Australian Diabetes Society.

\section{References}

${ }^{1}$ Herner B, Smedby B, Ysander L. Sudden illness as a cause of motor vehicle accidents. Br J Ind Med 1966; 23: 37-41.

${ }^{2}$ Leyshon GE, Elliott RW, Lyon J, Francis HWS. Diabetics and motorway crashes. $\mathrm{Br} \mathrm{Med} J$ 1972; ii: 404-5.

${ }^{3}$ Grattan E, Jeffcoate GO. Medical factors and road accidents. $\mathrm{Br}$ Med J 1968; i: 75-9.
4 Waller JA. Chronic medical conditions and traffic safety. Review of the California experience. $N$ Engl J Med 1965; 273: 1413-20.

${ }^{5}$ Crancer A, McMurray L. Accident and violation rates of Washington's medically restricted drivers. JAMA 1968; 205: 74-8.

${ }^{6}$ Ysander L. The safety of drivers with chronic disease. Br J Ind Med 1966; 23: 28-36.

${ }^{7}$ Ysander L. Diabetic motor-vehicle drivers without driving-licence restrictions. Acta Chir Scand 1970; suppl 409: 45-53.

${ }^{8}$ Frier BM, Matthews DM, Steel JM, Duncan LJP. Driving and insulin-dependent diabetes. Lancet 1980; i: 1232-4.

${ }^{9}$ Steel JM, Frier BM, Young RJ, Duncan LJP. Driving and insulin-dependent diabetes. Lancet 1981; ii: 354-6.

${ }^{10}$ Bailar JC, Ederer F. Significance factors for the ratio of a Poisson variable to its expectation. Biometrics 1964; 20: 639-43.

${ }^{11}$ Berkson J. Limitations of the application of fourfold table analysis to hospital data. Biometrics 1946; 2: 47-53.

${ }^{12}$ Liddell FDK. Motor vehicle accidents (1973-6) in a cohort of Montreal drivers. J Epidem Community Health 1982; 30: 140-5. 